\section{G541(P) PAEDIATRIC EARLY WARNING SCORES ARE A PREDICTOR OF ADVERSE OUTCOMES IN THE PREHOSPITAL SETTING: A NATIONAL COHORT STUDY}

${ }^{1}$ AR Corfield, ${ }^{2} \mathrm{D}$ Silcock, ${ }^{3} \mathrm{~L}$ Clerihew, ${ }^{4} \mathrm{P}$ Kelly, ${ }^{5} \mathrm{E}$ Stewart, ${ }^{5} \mathrm{H}$ Staines, ${ }^{5} \mathrm{~K}$ Rooney. ${ }^{1}$ Emergency Department, Royal Alexandra Hospital, Paisley, UK; ${ }^{2}$ Anaesthetic Department, Queen Elizabeth University Hospital, Glasgow, UK; ${ }^{3}$ Paediatric Department, Ninewells Hospital, Dundee, UK; ${ }^{4}$ Scottish Ambulance Service, Edinburgh, UK; ${ }^{5}$ Institute for Research in Healthcare Policy and Practice, University of the West of Scotland, Hamilton, UK

\subsection{6/archdischild-2020-rcpch.459}

Introduction Physiological deterioration often precedes clinical deterioration as patients develop critical illness. Use of a specific Paediatric Early Warning Score (PEWS), based on physiological measurements, may help identify children prior to their clinical deterioration and have been used for paediatric inpatients for many years. NHS Scotland has adopted a single national PEWS - PEWS (Scotland) with the intention the score is used throughout the whole patient journey. We aimed to assess whether a single set of observations recorded as a PEWS (Scotland) in an unselected group of paediatric ambulance patients could be a predictor of adverse outcome.

Methods We performed a retrospective cohort of all ambulance patients aged under 16 years conveyed to hospital in Scotland between 2011 and 2015. Patients were matched to their 30 day mortality and ICU admission using data linkage. Results Full results were available for 21,202 children and young people. On multivariate logistic regression, PEWS (Scotland) was an independent predictor of the primary outcome (ICU admission within $48 \mathrm{~h}$ or death within 30 days) with an odds ratio of 1.403 (95\%CI 1.349-1.460, $\mathrm{p}<0.001)$. Area Under Receiving Operator Curve (AUROC) for aggregated PEWS was 0.797 (95\% CI 0.759 to $0.836, p<0.001)$. The optimal PEWS using Youden's Index was 5.

\begin{tabular}{lll} 
Abstract G541(P) Table 1 & \\
\hline Effect & Odds Ratio & 95\% Cl and $p$ value \\
\hline Gender Female vs. Male & 0.930 & $(0.686-1.261) ; p=0.639$ \\
PEWS (Scotland) & 1.403 & $(1.349-1.460) ; p=<0.001$ \\
Patient Age & 1.003 & $(0.972-1.035) ; p=0.854$ \\
\hline
\end{tabular}

Discussion These data show PEWS (Scotland) to be a useful tool in a pre-hospital setting. A single set of physiological observations undertaken prior to arrival at hospital can identify a group of children at higher risk of an adverse in-hospital outcome. With the changing structure of receiving arrangements for paediatric patients, PEWS (Scotland) could allow for re-routing patients to appropriate receiving centres, when it is recognised that there is an increased risk of requiring active intervention including admission to intensive care, or the skills of a trauma team.

\section{G542(P) WHAT REALLY MATTERS? STANDARDS OF CARE IN CHILDREN AND YOUNG PEOPLE'S HEALTHCARE}

${ }^{1} \mathrm{R}$ Hannah, ${ }^{2} \mathrm{R}$ Conn, ${ }^{3} \mathrm{D}$ Hargreaves, ${ }^{3} \mathrm{E}$ Wortley, ${ }^{3} \mathrm{~J}$ Ruzangi, ${ }^{4} \mathrm{E}$ Sparrow, ${ }^{2} \mathrm{G}$ Davison. ${ }^{1}$ Department of Paediatrics, Royal Alexandra Children's Hospital, Brighton, UK; ${ }^{2}$ Centre for Medical Education, Queen's University, Belfast, UK; ${ }^{3}$ Department of Paediatrics, Imperial College Healthcare NHS Trust, London, UK; ${ }^{4}$ Royal College of Paediatrics and Child Health, London, UK

10.1136/archdischild-2020-rcpch.460
Background Measuring the quality of children and young people's (CYP's) healthcare services is an essential process for quality assurance, quality improvement and accountability, so that better care can be provided. Past quality measures created without CYP's input may have been missing 'what matters' to CYP themselves.

Aims

- To explore key features of healthcare quality measures most highly regarded by CYP's and consider factors influencing their priorities;

- To compare findings with parents and healthcare professionals (HCPs) perceptions of quality measures.

Method This qualitative study was undertaken as part of a Modified Delphi consensus study. CYP's, parents' and HCPs' views on 32 widely-used determinates for CYP's healthcare quality were captured during 3 separate focus group discussions. Measures were classified within General Practice, acute care and long-term care needs. Participants discussed the quality measure statements on which they had voted on during the day. Transcripts were coded by thematic analysis using NVivo12 software.

Results Participants included 12 CYP, 6 parents and 12 HCPs from a range of healthcare agencies.

CYP value measures that reflect co-production and partnership in decision-making. They desire flexibility and choice regarding their health needs (i.e. ownership of healthcare records and an individualised approach to transition). Measures such as the four-hour A\&E wait and annual weight measurements are considered arbitrary. CYP value seamless communication between services and offer digitalization of healthcare as a solution. Ideal measures should reflect a whole systems response with an identifiable patient outcome.

In contrast, parents value accessibility and convenience, whereas HCPs value family-centred care practices, timely communication and access to specialist services. CYPs and parents' priorities are informed by personal or family experience of illness, whereas professionals opinions reflect wider system structures.

All groups agreed that understanding and responding to emotional health was of vital importance. CYP want nonjudgemental, trusting relationships with HCP enabling open discussion about psychosocial health and wellbeing.

Discussion CYP offer a unique alternative perspective on the meaning of quality within quality measures. Service evaluation and improvement led by user-informed service measures will create a healthcare system which truly works with and for CYP in synchrony.

\section{G543(P) YOUNG PERSONS ROUNDS: A QUALITATIVE STUDY EXPLORING THE EXPERIENCES OF ADOLESCENTS ON ADULT WARDS}

R Johnson, J Connell, S Otley, M Travers, M loannou, C Datt, J Younis. Paediatrics and Child Health, UCL Medical School, London, UK

\subsection{6/archdischild-2020-rcpch.46}

Objective To explore the experiences and identify the needs of young adults and adolescents on adult wards at one teaching hospital; and to formulate interventions that will better meet these needs. 